\title{
All-trans retinoic acid prevents the development of type 1 diabetes by affecting the levels of interferon gamma and interleukin 4 in streptozotocin-induced murine diabetes model
}

\author{
Y. Wang ${ }^{1}$, Y.J. Zhong ${ }^{1}$, Y.Y. Wang ${ }^{2}$, J. Xing ${ }^{3}$ and Z.M. Wang ${ }^{4}$ \\ ${ }^{1}$ Department of Pediatrics, China-Japan Union Hospital of Jilin University, \\ Changchun, China \\ 2Department of Obstetrics and Gynecology, Baoshan Hospital of Panshi City, \\ Panshi, China \\ ${ }^{3}$ Department of Pediatrics, The second hospital of Jilin University, Changchun, China \\ ${ }^{4}$ Department of Ultrasonography, The Second Hospital of Jilin University, \\ Changchun, China
}

Corresponding author: Z.M. Wang

E-mail: wzhengmiao_ge3g@sina.com

Genet. Mol. Res. 15 (1): gmr.15017522

Received August 25, 2015

Accepted November 27, 2015

Published March 18, 2016

DOI http://dx.doi.org/10.4238/gmr.15017522

ABSTRACT. The aim of this study was to explore the molecular mechanism by which all-trans retinoic acid (ATRA) prevents type 1 diabetes mellitus (T1DM). Fifty ICR mice were randomly assigned to three groups: prevention group [ $\mathrm{N}=20$; mice received $10 \mathrm{mg} / \mathrm{kg}$ ATRA daily for 5 days and then $60 \mathrm{mg} / \mathrm{kg}$ streptozotocin (STZ) for 5 days]; diabetic group ( $\mathrm{N}=$ 20 , mice received $95 \%$ sterile peanut oil and $5 \%$ dimethyl sulfoxide for 5 days and then $60 \mathrm{mg} / \mathrm{kg} \mathrm{STZ}$ for 5 days); and control group ( $\mathrm{N}=10$, mice received $95 \%$ sterile peanut oil and $5 \%$ dimethyl sulfoxide for 5 days and then citrate buffer for 5 days). Blood glucose was measured using blood glucose test strips and serum insulin was measured by radioimmunoassay. Islets cell morphology was assessed by microscopy and ELISA was used 
to measure the serum levels of interferon gamma (IFN- $y$ ) and interleukin 4 (IL-4). In the prevention group, blood sugar levels were found to be reduced and serum insulin levels increased compared with the levels in the diabetic group $(P<0.05)$, indicating that ATRA prevented the STZinduced damage to islet cells. Meanwhile, ATRA was shown to decrease the levels of IFN-y and increase the levels of IL-4 as well as the IFN-Y/IL-4 ratio in STZ-treated animals $(P<0.05)$. These findings suggest that ATRA prevents the recurrence of autoimmune insulitis. This study demonstrated that ATRA effectively prevents the progression of T1DM in a murine model of the disease by reducing IFN-y levels and increasing IL-4 levels.

Key words: All-trans retinoic acid; Type 1 diabetes mellitus; Interferon gamma; Interleukin 4

\section{INTRODUCTION}

Type 1 diabetes mellitus (T1DM) results from the T cell-mediated destruction of $\beta$-cells in the pancreas-resident islets of Langerhans. Autoimmune diseases are characterized by $a$ significant reduction in insulin secretion; and imbalance and destruction of immune tolerance cytokines cause autoimmune disorders due to this lack of insulin (Berman et al., 1996; Rabinovitch and Suarez-Pinzon, 1998).

Vitamin A is an essential micronutrient and all-trans retinoic acid (ATRA) plays an important role in maintaining the active form of vitamin A in the context of immune regulation (Napoli, 1996). It has been shown that ATRA has protective effects in animal (Zunino et al., 2007) and in vitro cell culture (Kang et al., 2004) models of T1DM; however, the molecular mechanisms of the protective effects of ATRA on pancreatic islet remains unknown.

Here, a mouse model of T1DM was established by intraperitoneal injection of streptozotocin (STZ). The protective effects of ATRA on pancreatic $\beta$-cells of T1DM mice was investigated by assessing changes in the levels of interferon gamma (IFN- $\gamma$ ) and interleukin 4 (IL-4) as well as in the IFN- $\gamma / \mathrm{IL}-4$ ratio. All the results will provide the basic information for the prevention of human T1DM.

\section{MATERIAL AND METHODS}

\section{Reagents}

STZ was purchased from Sigma (St. Louis, MO, USA) and was suspended in $0.05 \mathrm{M}$ citrate buffer, while $10 \mathrm{mM}$ solution of ATRA (Sigma) was prepared in $100 \%$ ethanol for storage.

\section{Animals}

Fifty male diabetic ICR (Institute of Cancer Research) mice weighing $\sim 16-18 \mathrm{~g}$ were purchased from the Basic Medical Experimental Animal Center, Jilin University.

\section{Grouping}

Fifty ICR mice were fed 1 week after adaptation and were randomly assigned to three 
groups: the prevention group ( $N=20)$, in which mice received subcutaneous injection of ATRA (10 $\mathrm{mg} / \mathrm{kg}$ daily) for 5 days followed by 5 days intraperitoneal injection of STZ $(60 \mathrm{mg} / \mathrm{kg})$ for 5 days; diabetic group $(\mathrm{N}=20)$, in which mice received subcutaneous injections of $95 \%$ sterile peanut oil and $5 \%$ dimethyl sulfoxide for 5 days followed by intraperitoneal injection of STZ $(60 \mathrm{mg} / \mathrm{kg})$; and the control group $(\mathrm{N}=10)$, in which mice received subcutaneous injections of $95 \%$ sterile peanut oil and $5 \%$ DMSO for 5 days followed by intraperitoneal injection of citrate buffer for five days. Mice with blood glucose levels of $>16.7 \mathrm{mM}$ after 5 days of STZ injection were considered a suitable model for T1DM.

\section{Blood and tissue analyses}

Blood samples $(1 \mathrm{~mL}$ ) were collected from the tails of the experimental animals weekly and serum was collected from the blood by centrifugation. Blood glucose concentration was measured using blood glucose test strips (Roche, Indianapolis, IN, USA) and serum insulin levels were measured using an insulin radioimmunoassay kit (Weifang Three-dimensional Bio-engineering Co. Ltd., Weifang, China). Pancreatic pathology was assessed using hematoxylin-eosin staining and light microscopy of islet cells. INF- $\gamma$ and IL-4 levels were measured using a human interferon- $\gamma$ ELISA kit and an interleukin-4 ELISA Kit (Dakota for the Biotechnology Co., Ltd., Shenzhen, China), respectively.

\section{Statistical analysis}

All data were analyzed by SPSS11.0 and are reported as means \pm SD. Paired $t$-tests were used to compare data in the same group before and after treatment and ANOVA was used to compare data between groups. Differences with $\mathrm{P}<0.05$ were considered statistically significant.

\section{RESULTS}

\section{ATRA improves the physiology of T1DM in mice}

All mice in the control group grew normally and exhibited normal activity, weight, food and water intake, and urine output. In the diabetic group, most parameters (growth rate, daily activity, food and water intake, weight gain, and urine output) decreased compared with those in a control group. One mouse in the diabetic group died due to severe T1DM after 5 days of STZ administration. One mouse in the prevention group also died; however, most other mice in this group exhibited normal for growth rate, daily activity, food and water intake, weight gain, and urine output before and after intraperitoneal injection with STZ, indicating that ATRA improves the physiology of T1DM in mice by preventing the destruction caused by STZ.

\section{ATRA reduces the levels of blood glucose in T1DM mice models}

Before STZ treatment, there were no significant differences in the blood glucose levels between the mice in the three different groups (ATRA, diabetic, and control; $P>0.05$, Table 1). After 1 week of STZ treatment, blood glucose levels significantly increased in the diabetic group compared with the ATRA and control groups $(P<0.05$, Table 1). Blood glucose concentrations peaked in the 
diabetic group after 4 weeks of STZ administration $(P<0.05$, Table 1$)$. Similarly, the concentrations of blood glucose also peaked in prevention group after 4 weeks of STZ administration; however, the peak levels of blood glucose were significantly lower in the prevention group than in the diabetic group at the fourth week $(P<0.05$, Table 1$)$. In the control group, blood glucose levels did not differ significantly between the first week and the sixth week $(P>0.05$, Table 1$)$.

Table 1. Effects of ATRA on the blood glucose levels.
\begin{tabular}{l|c|c|c|c|c|c|c}
\hline Groups & Cases & Before STZ treatment (mM) & \multicolumn{4}{c}{ After STZ treatment (mM) } \\
\cline { 4 - 8 } & & 1 week & 2 weeks & 3 weeks & 4 weeks & 6 weeks \\
\hline Prevention & 19 & $6.02 \pm 0.59$ & $7.39 \pm 3.38^{\mathrm{c}}$ & $9.45 \pm 4.85^{\mathrm{c}}$ & $10.90 \pm 5.02^{\mathrm{c}}$ & $12.79 \pm 4.24^{\mathrm{c}}$ & $12.31 \pm 4.36^{\mathrm{c}}$ \\
\hline T1DM & 19 & $6.17 \pm 0.63$ & $9.81 \pm 4.28^{\mathrm{a}, \mathrm{b}}$ & $12.60 \pm 4.62^{\mathrm{b}}$ & $16.07 \pm 4.44^{\mathrm{b}}$ & $20.31 \pm 2.72^{\mathrm{b}}$ & $20.77 \pm 4.15^{\mathrm{b}}$ \\
\hline Control & 10 & $5.99 \pm 0.76$ & $5.86 \pm 0.68$ & $6.23 \pm 0.61$ & $6.05 \pm 0.58$ & $6.09 \pm 0.71$ & $6.51 \pm 0.67$ \\
\hline
\end{tabular}

${ }^{\text {aP }}<0.05$ versus prevention group; ${ }^{b} \mathrm{P}<0.05$ versus control group; ${ }^{\mathrm{c}} \mathrm{P}<0.05$ versus diabetic group.

\section{ATRA reduces the incidence of T1DM}

Before STZ treatment, there were no diabetic cases among the ATRA, the diabetic, and the control group animals (blood glucose $<7 \mathrm{mM}$ in all groups). After 1 week of STZ treatment, there was one diabetes case in the prevention group and two in the diabetic group. The incidence of diabetes increased with time in both the ATRA and diabetic groups (Table 2) and in the diabetic group, the incidence of diabetes was the highest at 4 weeks of STZ injection. In the control group, there were no diabetes cases from the first week to the sixth week (Table 2).

Table 2. Effects of ATRA on the incidence of diabetes.

\begin{tabular}{l|c|c|c|c|c}
\hline \multirow{2}{*}{ Groups } & \multicolumn{5}{|c}{ Diabetes incidence (\%) } \\
\cline { 2 - 6 } & 1 week & 2 weeks & 3 weeks & 4 weeks & 6 weeks \\
\hline Prevention & $5.3(1 / 19)^{\mathrm{a}}$ & $10.5(2 / 19)^{\mathrm{a}}$ & $26.3(5 / 19)^{\mathrm{a}}$ & $36.8(7 / 19)^{\mathrm{a}}$ & $36.8(7 / 19)^{\mathrm{a}}$ \\
\hline T1DM & $10.5(2 / 19)$ & $21.1(4 / 19)$ & $42.1(8 / 19)$ & $78.9(15 / 19$ & $84.2(16 / 19)$ \\
\hline Control & 0 & 0 & 0 & 0 & 0 \\
\hline
\end{tabular}

ap $<0.05$ versus the diabetic group.

\section{ATRA improves serum insulin levels}

Before STZ treatment commenced, there was no difference in the serum levels of insulin between the ATRA, diabetic, and control groups ( $P>0.05)$. After 6 weeks of STZ treatment, there was a marked decrease in the serum insulin in the prevention group compared with the control group $(P<0.05$, Table 3); however, the serum insulin in the diabetic group was lower than the levels in both the ATRA and control groups $(P<0.05$, Table 3$)$. In the control group, serum insulin levels did not differ between the different weeks $(P>0.05)$.

Table 3. Effects of ATRA on serum insulin levels.

\begin{tabular}{l|c|c|c|c|c}
\hline \multirow{2}{*}{ Groups } & \multicolumn{5}{|c}{ Serum insulin $(\mathrm{IU} / \mathrm{mL})$} \\
\cline { 2 - 7 } & 1 week & 2 weeks & 3 weeks & 4 weeks & 6 weeks \\
\hline Prevention & $28.51 \pm 3.24^{\mathrm{a}, \mathrm{b}}$ & $30.21 \pm 2.99^{\mathrm{a}, \mathrm{b}}$ & $31.58 \pm 3.25^{\mathrm{a}, \mathrm{b}}$ & $31.94 \pm 3.25^{\mathrm{a}, \mathrm{b}}$ & $32.64 \pm 3.89^{\mathrm{a}, \mathrm{b}}$ \\
\hline T1DM & $26.77 \pm 2.12^{\mathrm{a}}$ & $25.74 \pm 2.62^{\mathrm{a}}$ & $24.51 \pm 2.84^{\mathrm{a}}$ & $24.89 \pm 2.57^{\mathrm{a}}$ & $23.81 \pm 2.95^{\mathrm{a}}$ \\
\hline Control & $41.98 \pm 6.12$ & $42.14 \pm 6.88$ & $42.77 \pm 7.14$ & $41.58 \pm 6.69$ & $42.92 \pm 7.7$ \\
\hline
\end{tabular}

${ }^{\mathrm{a} P}<0.05$ versus the control group; ${ }^{\mathrm{b}} \mathrm{P}<0.05$ versus the diabetic group. 


\section{ATRA prevents the development of pancreatic pathology}

The islets of mice in the control group of this study were found to have favorable morphological characteristics: most cells were oval-shaped with clear boundaries. A larger number of islet cells were arranged neatly and nuclei was round or oval in shape (Figure 1A). The number of islets cells in the mice in the prevention group was slightly lower than that in control group mice; however, in the prevention group animal islet cells exhibited normal morphology. Most islet cells in the prevention group mice exhibited extensive cytoplasmic swelling and degeneration (Figure 1B). In the diabetic group, islet number was significantly lower than that in the control group and many shrinking cells with indistinct boundaries were observed. Nuclei were furthermore shown to be irregular in shape and degraded. A few infiltrating lymphocytes and mononuclear cells were observed in the diabetic group islets (Figure 1C).

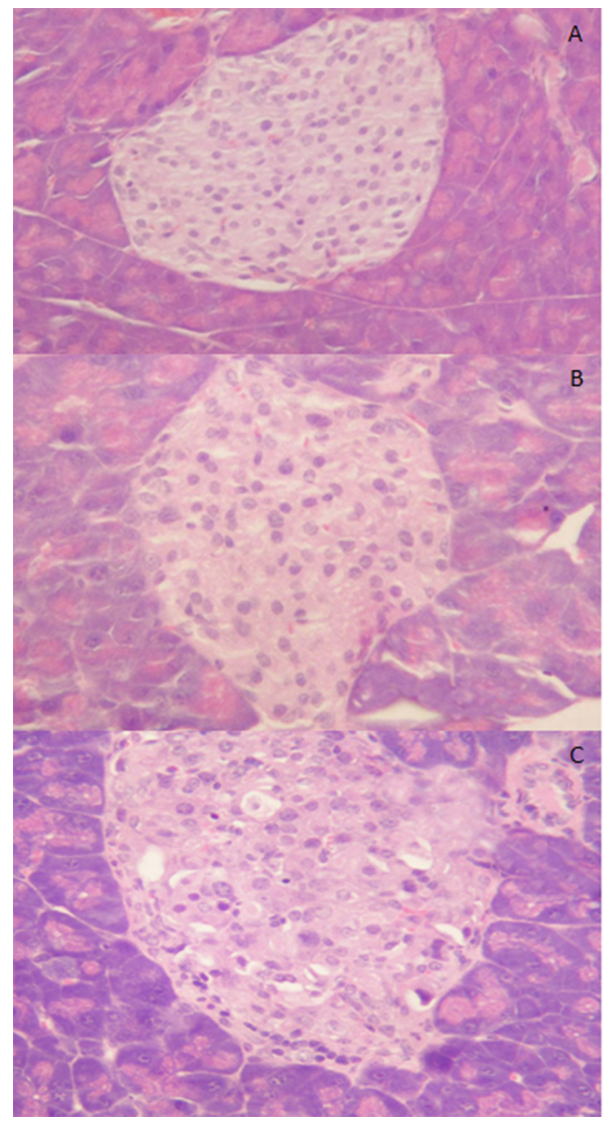

Figure 1. Effects of ATRA on the development of pancreatic pathology. A. Islet cells in the control group were oval with clear boundaries. Many islet cells were arranged neatly and nuclei were round or oval. B. Islet numbers were slightly lower in the prevention group compared with the control group; however, the islet cells exhibited normal morphology in prevention group mice. Most cells, however, exhibited extensive cytoplasmic swelling or degeneration in control group mice. C. Islet numbers were significantly lower in the diabetic group than in the control group. Most cells were shrunken and had undefined boundaries, while nuclei were in irregular shape or degraded. Some infiltrating lymphocytes and mononuclear cells were present. 


\section{Effects of ATRA on the serum levels of IFN-y and IL-4}

The serum levels of IFN- $\gamma$ and IL-4 in the diabetic group animals were shown to be significantly higher and lower, respectively, than those in the prevention and control group animals; while the IFN- $\gamma / \mathrm{IL}-4$ ratio was found to be markedly higher in the diabetic group than in the prevention and control groups $(P<0.05$, Table 4$)$. In the prevention group, the serum IFN- $\gamma$ and IL-4 levels were significantly lower and higher, respectively, than in the diabetic group $(P<0.05$, Table 4). Compared with the levels measured for the prevention group, the serum levels of IFN- $\gamma$ were significantly lower in the control group $(P<0.05$, Table 4$)$, while there was little difference between the levels of IL-4 in the control group compared with prevention group $(P>0.05$, Table 4). These findings suggest that ATRA reduces the levels of IFN- $\gamma$ and increases the levels of IL-4 in the serum.

Table 4. Serum levels of IFN- $\gamma$ and IL-4 after six weeks of STZ treatment.

\begin{tabular}{l|c|c|c|c}
\hline Groups & Cases & IFN- $\gamma(\mathrm{pg} / \mathrm{mL})$ & $\mathrm{IL}-4(\mathrm{pg} / \mathrm{mL})$ & IFN- $\gamma / \mathrm{IL}-4$ \\
\hline Prevention & 10 & $34.09 \pm 3.03^{\mathrm{b}}$ & $39.89 \pm 5.88^{\mathrm{b}}$ & $0.87 \pm 0.15^{\mathrm{b}}$ \\
\hline T1DM & 12 & $53.20 \pm 9.07^{\mathrm{a}}$ & $22.31 \pm 6.00^{\mathrm{a}}$ & $2.54 \pm 0.80^{\mathrm{a}}$ \\
\hline Control & 8 & $29.04 \pm 3.34$ & $40.84 \pm 10.54$ & $0.74 \pm 0.18$ \\
\hline
\end{tabular}

${ }^{\mathrm{a} P}<0.05$ versus the control group; ${ }^{\mathrm{b}} \mathrm{P}<0.05$ versus the diabetic group.

\section{DISCUSSION}

Patients with T1DM have been shown to have low levels of vitamin A compared with healthy people, suggesting that vitamin A plays an important role in normal metabolism and thus that vitamin A deficiency affects immune regulation, leading to T1DM (Basu and Basualdo, 1997; Baena et al., 2002; Sia, 2005). Vitamin A was previously shown to reduce the incidence of T1DM in nucleotide-binding oligomerization domain (NOD) mice (Zunino et al., 2007) and ATRA is known to protect an insulin-producing cell line (RINm5F) from glucotoxicity by reducing glucose-induced damage (Kang et al., 2004; Jin et al., 2010). In this study, ATRA was shown to preserve islet cell numbers and inhibit STZ-induced increases in cell size. The STZ-induced impairment of insulin secretion was found to be prevented by ATRA in this study, demonstrating a protective effect of ATRA on STZ-treated pancreatic $\beta$-cells. Treatment with ATRA was furthermore shown to reverse the concentration decreases and weight loss caused by STZ. Together, these findings suggest that ATRA decreases the incidence of STZ-induced T1DM in a mouse model.

All-trans retinoic acid has been found to regulate immune processes via cytokine regulation. Vitamin A deficiency disrupts the balance of Th1/Th2, which leads to an increase in the levels of Th1 and a decrease in the levels of Th2 (Nikawa et al., 1999; Farhangi et al., 2013). Vitamin A activates Th2 responses and reduces Th1 responses (Lovett-Racke and Racke, 2002); and ATRA has been shown to reduce the expression of Th1 and increase the expression of Th2 in human lymphocytes (Dawson et al., 2006). Increased ATRA levels induce IL-4 gene expression in myelin basic protein-specific T cells, which consequently express a Th1-like phenotype (Lovett-Racke and Racke, 2002), while ATRA deficiency has been found to result in an increase in the number of Th1 cells (Nozaki et al., 2006). Retinoic acid has been shown to delay the differentiation and maturation of dendritic cells, reduce the activity of lymphocyte reaction, reduce Thl cytokine production, and increase Th2 cytokines, thereby causing a shift of the immune response to Th2 (Bai et al., 2010; 
Wansley et al., 2013; Wu et al., 2013; Yokota-Nakatsuma et al., 2014). These observations suggest that ATRA regulates the Th1/Th2 balance by regulating the expression of cytokines, specifically by inhibiting Th1 cell activity and elevating the number of Th2 cells.

The cytokines IFN- $\gamma$ and IL-4 play important roles in the immune system (Figure 2). Many environmental factors including geographic location and alcohol consumption affect the development of inflammation; and certain pathogens have been found to increase the incidence of diabetes (Erben et al., 2013; Haeseker et al., 2013; Schara et al., 2013; Gogeneni et al., 2015). Microbial components such as flagellin, peptidoglycan, and lipopolysaccharide are recognized by receptors such as toll-like receptors (TLRs), NOD, and antigen-presenting cells (APCs). The TLR activates $\mathrm{NF}-\kappa \mathrm{B}$, resulting in an inflammatory response. The differentiation of naïve $\mathrm{T}$ cells into Th1, Th17, Th2, and natural killer T cells is mediated by APCs; and Th1 and Th17 cells produce IFN- $\gamma$ and IL-17 and -22 , respectively, while Th2 cells produce IL-4, -5 , and -10 . The cytokines IFN- $\gamma$ and IL-4, on the other hand, can affect the Th1/Th2 balance.

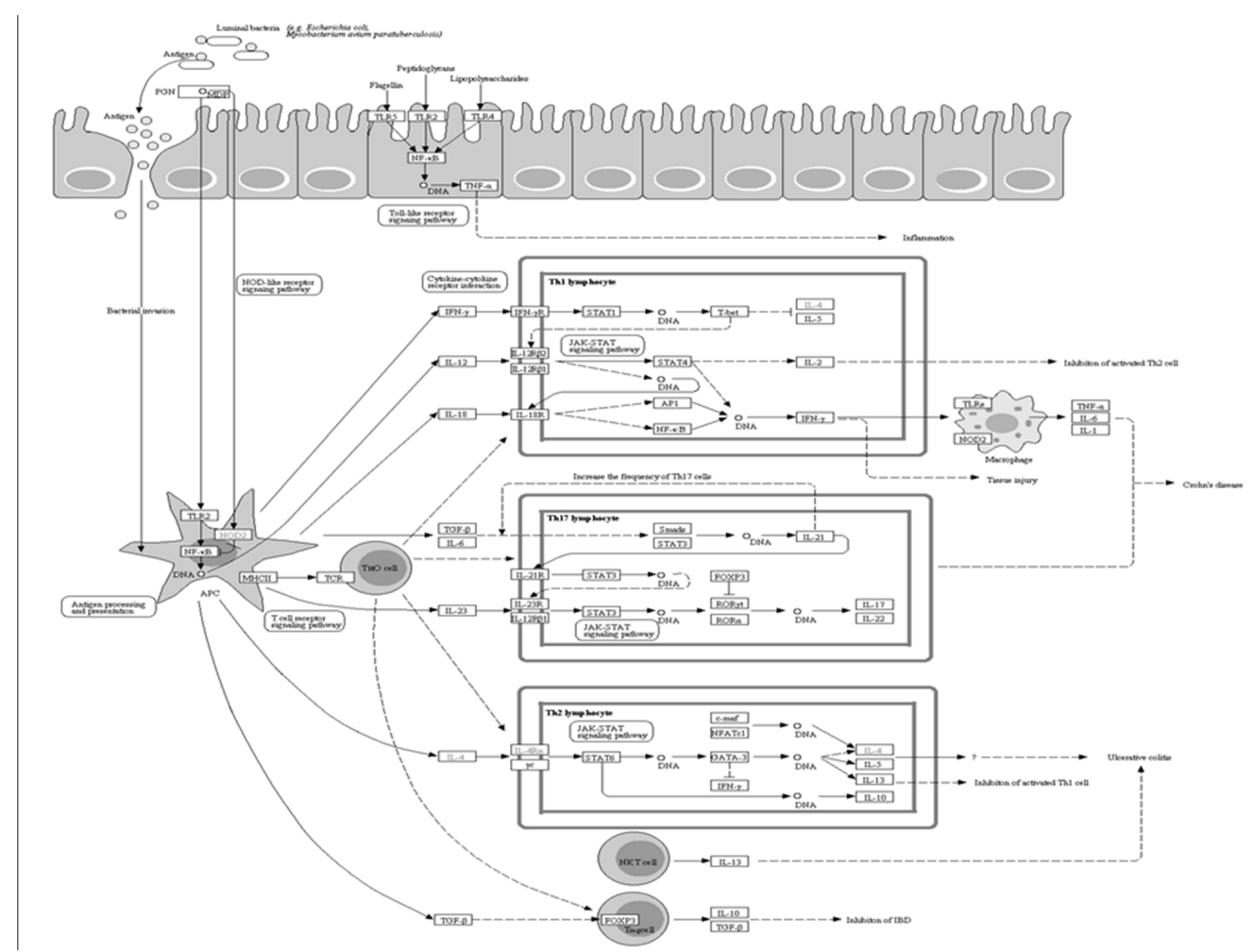

Figure 2. Effects of ATRA on immune response-associated IFN- $\gamma$ and IL-4. IFN- $\gamma$ and IL-4 are involved in most immune responses. Many environmental factors including geographical location and alcohol consumption affect the development of inflammation and several pathogens have been found to increase the incidence of T1DM. Microbial components such as flagella, peptidoglycan, and lipopolysaccharide are recognized by receptors such as toll-like receptors (TLRs), nucleotide-binding oligomerization domain (NOD), and antigen-presenting cells (APCs). The TLR activates NF-kB, resulting in inflammatory responses. The differentiation of naïve T cells into Th1, Th17, Th2, and natural killer T cells is mediated by APCs and Th1 and Th17 produce IFN- $\gamma$ and IL-17 and -22, respectively.Th2 cells produce IL-4, -5 , and -10 . Both IFN- $\gamma$ and IL-4 affect the Th1/Th2 balance. 
Accordingly, the findings of this study demonstrate that ATRA adjusts the IFN- $\gamma /$ IL-4 imbalance caused by the STZ-induced decrease in IFN- $\gamma$ levels, increase in IL-4 levels, and the resulting reduced IFN- $\gamma / \mathrm{IL}-4$ ratio. In this way, ATRA significantly reduces STZ-induced islet inflammation and prevents damage to pancreatic islet $\beta$-cells. The findings reported here are consistent with previous reports (Nieman et al., 2004; Sodhi and Singh, 2013). The effects of ATRA on Th2-type cytokines such as IL-4 are currently being investigated, and ATRA has furthermore been found to reduce the levels of Th1-type cytokines such as IFN- $\gamma$ and IL-1 $\beta$, thereby reducing $\beta$-cell cytotoxicity and protecting islet cells from damage caused by, for example, STZ-induced nonspecific insulitis. Previous research demonstrated that ATRA protects the RIN-m5F $\beta$-cell line by decreasing the levels of IL-1 $\beta$, TNF- $\alpha$, and IFN- $\gamma$, allowing islet cell numbers to recover to normal levels. This effect may involve the ATRA-induced decrease in NO release; however, further investigation is required to confirm this hypothesis.

In this study, a mouse model of T1DM was established by repeated injection of mice with STZ. Using this model, it was shown that ATRA reduces the incidence of T1DM by protecting islet $\beta$-cells, upregulating the levels of the pancreatic $\beta$-cell factor IL-4, reducing the cell toxicityassociated levels of IFN- $\gamma$ in $\beta$-cells, and maintaining the Th1/Th2 balance. Vitamin A deficiency is associated with the pathogenesis of T1DM, and the multiple functions of ATRA therefore need further study in the context of T1DM. The findings reported here; however, provide supporting evidence that ATRA may have potential as a drug for the prevention of T1DM in the future.

\section{REFERENCES}

Baena RM, Campoy C, Bayés R, Blanca E, et al. (2002). Vitamin A, retinol binding protein and lipids in type 1 diabetes mellitus. Eur. J. Clin. Nutr. 56: 44-50. http://dx.doi.org/10.1038/s.ejcn.1601279

Bai A, Lu N, Zeng H, Li Z, et al. (2010). All-trans retinoic acid ameliorates trinitrobenzene sulfonic acid-induced colitis by shifting Th1 to Th2 profile. J. Interferon Cytokine Res. 30: 399-406. http://dx.doi.org/10.1089/jir.2009.0028

Basu TK and Basualdo C (1997). Vitamin A homeostasis and diabetes mellitus. Nutrition 13: 804-806. http://dx.doi.org/10.1016/ $\underline{\text { S0899-9007(97)00192-5 }}$

Berman MA, Sandborg Cl, Wang Z, Imfeld KL, et al. (1996). Decreased IL-4 production in new onset type I insulin-dependent diabetes mellitus. J. Immunol. 157: 4690-4696.

Dawson HD, Collins G, Pyle R, Key M, et al. (2006). Direct and indirect effects of retinoic acid on human Th2 cytokine and chemokine expression by human T lymphocytes. BMC Immunol. 7: 27. http://dx.doi.org/10.1186/1471-2172-7-27

Erben N, Ozgunes I, Aksit F, Doyuk Kartal E, et al. (2013). Healthcare-associated infections and the distribution of causative pathogens in patients with diabetes mellitus. Eur. J. Clin. Microbiol. Infect. Dis. 32: 821-825. http://dx.doi.org/10.1007I $\underline{\text { s10096-013-1816-x }}$

Farhangi MA, Keshavarz SA, Eshraghian M, Ostadrahimi A, et al. (2013). Vitamin A supplementation and serum Th1- and Th2associated cytokine response in women. J. Am. Coll. Nutr. 32: 280-285. http://dx.doi.org/10.1080/07315724.2013.816616

Gogeneni H, Buduneli N, Ceyhan-Öztürk B, Gümüş P, et al. (2015). Increased infection with key periodontal pathogens during gestational diabetes mellitus. J. Clin. Periodontol. 42: 506-512. http://dx.doi.org/10.1111/jcpe.12418

Haeseker MB, Pijpers E, Dukers-Muijrers NH, Nelemans P, et al. (2013). Association of cytomegalovirus and other pathogens with frailty and diabetes mellitus, but not with cardiovascular disease and mortality in psycho-geriatric patients; a prospective cohort study. I \& A 10: 30.

Jin CJ, Hong CY, Takei M, Chung SY, et al. (2010). All-trans retinoic acid inhibits the differentiation, maturation, and function of human monocyte-derived dendritic cells. Leuk. Res. 34: 513-520. http://dx.doi.org/10.1016/j.leukres.2009.10.006

Kang MK, Yoon YE, Yang JY, Kwon KB, et al. (2004). Protective effect of retinoic acid on interleukin-1 beta-induced cytotoxicity of pancreatic beta-cells. Mech. Ageing Dev. 125: 483-490. http://dx.doi.org/10.1016/j.mad.2004.04.006

Lovett-Racke AE and Racke MK (2002). Retinoic acid promotes the development of Th2-like human myelin basic proteinreactive T cells. Cell. Immunol. 215: 54-60. http://dx.doi.org/10.1016/S0008-8749(02)00013-8

Napoli JL (1996). Biochemical pathways of retinoid transport, metabolism, and signal transduction. Clin. Immunol. Immunopathol. 80: S52-S62. http://dx.doi.org/10.1006/clin.1996.0142 
Nieman KM, Rowling MJ, Garrow TA and Schalinske KL (2004). Modulation of methyl group metabolism by streptozotocininduced diabetes and all-trans-retinoic acid. J. Biol. Chem. 279: 45708-45712. http://dx.doi.org/10.1074/jbc.M408664200

Nikawa T, Odahara K, Koizumi H, Kido Y, et al. (1999). Vitamin A prevents the decline in immunoglobulin A and Th2 cytokine levels in small intestinal mucosa of protein-malnourished mice. J. Nutr. 129: 934-941.

Nozaki Y, Tamaki C, Yamagata T, Sugiyama M, et al. (2006). All-trans-retinoic acid suppresses interferon-gamma and tumor necrosis factor-alpha; a possible therapeutic agent for rheumatoid arthritis. Rheumatol. Int. 26: 810-817. http://dx.doi. org/10.1007/s00296-005-0076-1

Rabinovitch A and Suarez-Pinzon WL (1998). Cytokines and their roles in pancreatic islet beta-cell destruction and insulindependent diabetes mellitus. Biochem. Pharmacol. 55: 1139-1149. http://dx.doi.org/10.1016/S0006-2952(97)00492-9

Schara R, Skaleric E, Seme K and Skaleric U (2013). Prevalence of periodontal pathogens and metabolic control of type 1 diabetes patients. J. Int. Acad. Periodontol. 15: 29-34.

Sia C (2005). Imbalance in Th cell polarization and its relevance in type 1 diabetes mellitus. Rev. Diabet. Stud. 2: $182-186$. http://dx.doi.org/10.1900/RDS.2005.2.182

Sodhi RK and Singh N (2013). All-trans retinoic acid rescues memory deficits and neuropathological changes in mouse model of streptozotocin-induced dementia of Alzheimer's type. Prog. Neuropsychopharmacol. Biol. Psychiatry 40: 38-46. http:// dx.doi.org/10.1016/j.pnpbp.2012.09.012

Wansley DL, Yin Y and Prussin C (2013). The retinoic acid receptor- $\alpha$ modulators ATRA and Ro415253 reciprocally regulate human IL-5+ Th2 cell proliferation and cytokine expression. Clin. Mol. Allergy 11: 4. http://dx.doi.org/10.1186/1476-7961$\underline{11-4}$

Wu J, Zhang Y, Liu Q, Zhong W, et al. (2013). All-trans retinoic acid attenuates airway inflammation by inhibiting Th2 and Th17 response in experimental allergic asthma. BMC Immunol. 14: 28. http://dx.doi.org/10.1186/1471-2172-14-28

Yokota-Nakatsuma A, Takeuchi H, Ohoka Y, Kato C, et al. (2014). Retinoic acid prevents mesenteric lymph node dendritic cells from inducing IL-13-producing inflammatory Th2 cells. Mucosal Immunol. 7: 786-801.

Zunino SJ, Storms DH and Stephensen CB (2007). Diets rich in polyphenols and vitamin A inhibit the development of type I autoimmune diabetes in nonobese diabetic mice. J. Nutr. 137: 1216-1221. 